\section{Javier \\ Maseda Rodríguez}

Universidad de

Santiago de Compostela, España javier.maseda@usc.es Recibido: 19.02.18 Aceptado: 1.08 .18

\title{
Crisis matrimoniales y la reforma de las reglas domésticas españolas de competencia judicial internacional: paso adelante o paso atrás
}

\section{Matrimonial proceedings and the amendment of Spanish domestic rules of international jurisdiction: step forward or step back}

Resumen: Este trabajo tiene por objeto analizar la reciente reforma de las normas domésticas españolas de competencia judicial internacional en materia de crisis matrimoniales. Estas reglas son aplicables en ciertos casos aun cuando la vinculación de los operadores jurídicos españoles (y de los Estados miembros de la UE) por el Reglamento (CE) núm. 2201/2003, del Consejo, de 27 de noviembre de 2003, relativo a la competencia, el reconocimiento y la ejecución de resoluciones judiciales en materia matrimonial y de responsabilidad parental. Se examina la nueva normativa doméstica en su comparación con la derogada, con la intención de determinar si mejora el sistema o, por contrario, no había razón para modificar el régimen anterior.

Palabras clave: Crisis matrimoniales internacionales; competencia judicial internacional: normativa doméstica española; Reglamento (CE) 2001/2003.
Abstract: The purpose of this paper is to analyze briefly the recent amendment of the Spanish domestic rules of international jurisdiction in matrimonial matters. They are applicable in certain cases even despite the applicability for Spain (and all the Member States of the EU) of the Council Regulation (EC) 2201/2003, of 27 November 2003, concerning jurisdiction and the recognition and enforcement of judgments in matrimonial matters and the matters of parental responsibility, repealing Regulation (EC) 1347/2000. This essay analyzes the new domestic Spanish rules in comparison with the repealed ones, in order to determine the improvement of the system or, on the contrary, the absence of reason to modify the previous regime.

Keywords: Matrimonial proceedings; International jurisdiction: Spanish domestic rules; Regulation (EC) 2201/2003. 
Desde el punto de vista del ordenamiento jurídico español, así como de cualquier otro Estado miembro de la Unión Europea (UE), la competencia judicial internacional en materia de crisis matrimoniales, esto es, en relación a las causas matrimoniales de separación judicial, divorcio y nulidad matrimonial, se determina, como es sabido, y dentro del conjunto de medidas elaboradas en sede de cooperación judicial en materia civil en orden al establecimiento progresivo de un espacio de libertad, seguridad y justicia en la UE, por el Reglamento (CE) núm. 2201/2003, del Consejo, de 27 de noviembre de 2003, relativo a la competencia, el reconocimiento y la ejecución de resoluciones judiciales en materia matrimonial y de responsabilidad parental'.

Aplicable desde el 01 de marzo de 2005 (art. 72 R. 2201), el Reglamento 2201/2003 constituye el régimen regulador preferente a la hora de determinar la competencia judicial internacional de las autoridades españolas y del resto de Estados miembros, con la excepción de Dinamarca, en las causas de divorcio, separación judicial y nulidad del matrimonio2: no solo deroga el anterior Reglamento (CE) núm. 1347/2000, de 29 de mayo de 2000, relativo a la competencia, el reconocimiento y la ejecución de resoluciones judiciales en materia matrimonial y de responsabilidad parental sobre los hijos comunes ${ }^{3}$, encargado de estas cuestiones desde el 01 de marzo de 2001 hasta la entrada en vigor del actual instrumento (Considerando núm. 28 R. 2201; art. 71 R. 2201), también prevalece sobre cualquier Convenio bilateral o multilateral existente entre los Estados UE, regulando esta materia (Fernández y Sánchez, 2016, p. 449).

La consulta de las disposiciones del Reglamento 2201/2003 permitirá al Tribunal o autoridad española, así como a cualquier otro juez o autoridad de un Estado miembro, determinar si disfruta (o no) de competencia judicial internacional respecto de una demanda de separación judicial o de disolución del vínculo conyugal. Y lo hará a partir de una serie de foros exclusivos de competencia judicial internacional (Fernández y Sánchez, 2016, p. 450) ${ }^{4}$, recogidos básicamente en los arts. 3 a 5 R. 2201, que operan de manera alternativa y no jerárquica ${ }^{5}$, que son verificables de oficio (Fernández y Sánchez, 2016, p. 450) ${ }^{6}$, y que tienen un alcance objetivo, entre los que no figura ninguno basado en el ejercicio de la autonomía de la voluntad, ni expreso ni tácito (Palao, 2014, p. 469): se fundamentan, principalmente y como puede verse en el art. 3 R. 2201, en los criterios de la residencia habitual de los cónyuges, residencia habitual del demandante o del demandado, y nacionalidad común

\footnotetext{
${ }^{1}$ DOUE L 338/1, de 23 de diciembre de 2003. Se está trabajando en varias modificaciones en este Reglamento 2201/2003, que pueden consultarse en Propuesta de Reglamento del Consejo relativo a la competencia, el reconocimiento y la ejecución de resoluciones en materia matrimonial y de responsabilidad parental, y sobre la sustracción internacional de menores (refundición) (COM (2016) 411 Final), que afectan básicamente a la responsabilidad parental, y no a las crisis matrimoniales, que es donde se enmarca este trabajo.

${ }_{2}^{2}$ Actúan correctamente los operadores jurídicos españoles, aplicando el Reglamento 2201/2003 y desechando el Derecho nacional o autónomo, en la Sent. AP de Barcelona de 31 de enero de 2014 (JUR 2014\52492), respecto de unos litigantes de Senegal; en la Sent. AP de Guadalajara de 02 de mayo de 2013 (AC 2013\1325), respecto de cónyuges ecuatorianos; o en Sent. AP de Barcelona de 30 de junio de 2015 (AC 2015\1435), respecto de una demanda de divorcio y medidas parentales entre cónyuges de nacionalidad distinta y sin residencia habitual común en España, reconociendo la demandante no haber residido durante al menos un año inmediatamente antes de la presentación de la demanda. No lo hacen, en cambio, en otras resoluciones, donde aplican el régimen doméstico ignorando la existencia del Reglamento 2201/2003; así, por ejemplo, en la Sent. AP de Girona de 09 de septiembre de 2013 (JUR 2013\348015), respecto de unos cónyuges marroquíes; Sent. AP de Barcelona de 16 de mayo de 2006, respecto de unos cónyuges chilenos con residencia habitual en España; o en Auto AP de Álava de 28 de noviembre de 2007 (JUR 2008\38696), en relación a un divorcio entre un demandado con residencia habitual en Cuba y un demandante residente en España.

${ }^{3}$ DOCE L 160/19, de 30 de junio de 2000.

${ }^{4}$ En cualquier caso, no debe confundirse este término: exclusivo tiene equivalencia con limitativo, en el sentido de que no pueden operar más foros que los referidos en el Reglamento 2201/2003, y no con un supuesto carácter jerárquico o privilegiado; así, Gaudemet-Tallon, H., "Le Reglement no 1347/2000 du Conseil du 29 mai 2000: "Compétence, reconnaissance et exécution des décisions en matiere matrimoniale et en matiere de responsabilité parentale des enfants communs", Journ. dr. int., 2001-II, pp. 381-430, espec. p. 395.

${ }^{5}$ En la práctica, por ejemplo, el Auto AP de Barcelona de 25 de julio de 2011 (JUR 2011 307654 ), respecto de un divorcio entre cónyuges españoles con residencia habitual en Bolivia.

${ }^{6}$ Lo indica, por ejemplo, el $t$ (JUR 2011\199446).

7 Véase, asimismo, Considerando núm. 31 del "Informe Explicativo del Convenio celebrado con arreglo al art. K.3 del Tratado de la Unión Europea, sobre la competencia, el reconocimiento y la ejecución de resoluciones judiciales en materia Matrimonial”, Borrás Rodríguez, A., DOUE C 221/27, de 16 de julio de 1998.
} 
de los cónyuges (Sánchez, 2013, p. 33) .

Regulador exclusivamente de las cuestiones de competencia judicial internacional relativas a la relajación o disolución del vínculo matrimonial, no se ocupa el Reglamento 2201/2003, en cambio, de la competencia judicial internacional en materias vinculadas a las crisis matrimoniales, como son las causas de divorcio, las consecuencias patrimoniales de la disolución del matrimonio $u$ otras posibles medidas principales $\mathrm{o}$ accesorias, así como el régimen económico matrimonial, el uso de la vivienda común, los alimentos para los hijos o la pensión compensatoria. Cada una de estas cuestiones disfruta de su propio régimen aplicable a la hora de determinar la competencia judicial internacional de un juez o autoridad de un Estado miembro; o, lo que es lo mismo, la eventual competencia judicial internacional de un tribunal comunitario a partir del Reglamento 2201/2003 respecto de una eventual demanda relativa a la crisis matrimonial, no supone necesariamente su competencia tampoco para aquellas otras cuestiones litigiosas que frecuentemente acompañan a la demanda de separación judicial y/o divorcio, sometidas, en cada caso, a su régimen aplicable correspondiente. De ahí que se hable de la dispersión internacional del pleito como uno de los caracteres del derecho internacional privado comunitario de familia (Orejudo Prieto, 2014, par. II.1.A) .

Ahora bien, la aplicación del Reglamento 2201/2003 a la hora de determinar la competencia judicial internacional en relación a las causas matrimoniales de separación judicial, divorcio y nulidad matrimonial no va a suponer, desde el punto de vista del ordenamiento jurídico español, como tampoco desde la óptica de cualquier otro ordenamiento jurídico de un Estado UE, la eliminación y eventual juego de los foros autónomos, nacionales o domésticos sobre competencia en materia de crisis matrimoniales. Tal es lo que dispone el art. 7 R. 2201 cuando habla de los foros nacionales dentro de lo que el legislador europeo entiende como "la competencia

\footnotetext{
${ }^{8}$ Muchas de las referencias de este trabajo se dirigen genéricamente a la competencia judicial internacional de jueces y Tribunales. No obstante, los criterios de competencia del Reglamento 2201/2003 resultan asimismo aplicables a la hora de determinar la competencia de las autoridades nacionales que, en este ámbito, tengan funciones equivalentes a las propias de una autoridad judicial (por ejemplo, en el ordenamiento jurídico español, los notarios, en tanto que, de acuerdo con el art. 54 Ley Notarial y los arts. 82 y 87 Código civil español, pueden separar o divorciar de mutuo acuerdo, siempre que los cónyuges no tengan hijos menores no emancipados o con la capacidad modificada judicialmente que dependan de ellos). Repárese, en este sentido, en la Propuesta de Reglamento del Consejo relativo a la competencia, el reconocimiento y la ejecución de resoluciones en materia matrimonial y de responsabilidad parental, y sobre la sustracción internacional de menores (refundición), cuando, a lo largo del texto, propone la supresión de las referencias a jueces, Tribunales, órganos, resoluciones o autoridades judiciales por un genérico autoridades.

${ }^{9}$ Criticando esta fragmentación, Sánchez (2013, p. 44), Arenas (2004, pp. 139-140) y, desarrollando esta cuestión, pp. 65-109. Lo vemos respecto de la custodia de los hijos, cuya competencia se determina a partir del Reglamento 2201/2003 en lo que es su parte relativa a responsabilidad parental, regulada por medio de reglas de competencia distintas de aquéllas propias de las crisis matrimoniales (por ejemplo, Sent. AP de Cantabria de 13 de junio de 2008, JUR 2008\329565, en relación a un divorcio entre cónyuges peruanos y competencia respecto de los derechos de visita de los abuelos sobre los menores), así como del Convenio de La Haya de 19 de octubre de 1996 relativo a la competencia, la ley aplicable, el reconocimiento, la ejecución y la cooperación en materia de responsabilidad parental y de medidas de protección de los niños. Y así sucede también respecto de las obligaciones alimenticias y las pensiones posteriores al divorcio (por ejemplo, el Auto AP de Valencia de 14 de enero de 2003, JUR 2003\92936, o el Auto AP de Cádiz de 15 de septiembre de 2005 JUR 2006\30518), regulada la competencia judicial internacional por medio del Reglamento (CE) núm. 4/2009, del Consejo, de 18 de diciembre de 2008, relativo a la competencia, la ley aplicable, el reconocimiento y la ejecución de las resoluciones y la cooperación en materia de obligaciones de alimentos (DOUE L 7/1, de 10 de enero de 2009. En la práctica, por ejemplo, Auto AP de Valencia de 14 de enero de 2003, JUR 2003\92936, en relación a un exequatur de una sentencia alemana, el tribunal desechó, en lo que ahora interesa, la aplicación del Reglamento 1347/2000 al excluir este los alimentos y pensión compensatoria; o, en el mismo sentido, Auto AP de Cádiz de 15 de septiembre de 2005, JUR 2006\30518). Téngase en cuenta, asimismo, la nueva normativa europea reguladora de los regímenes económico-matrimoniales, que, en régimen de cooperación reforzada, recoge el Reglamento (UE) 2016/1103, del Consejo, de 24 de junio de 2016, por el que se establece una cooperación reforzada en el ámbito de la competencia, la ley aplicable, el reconocimiento y la ejecución de resoluciones en materia de regímenes económicos matrimoniales (DOUE L 183/1, de 08 de julio de 2016; también, Reglamento (UE) 2016/1104, del Consejo, de 24 de junio de 2016, por el que se establece una cooperación reforzada en el ámbito de la competencia, la ley aplicable, el reconocimiento y la ejecución de resoluciones en materia de efectos patrimoniales de las uniones registradas, DOUE L 183/30, de 08 de julio de 2016).Con todo, consciente el legislador europeo de esta realidad, son habituales las reglas que favorecen la acumulación de causas ante un mismo órgano jurisdiccional o autoridad (por ejemplo, art. 8 R. 2201, que permite reclamar por cuestiones relativas a responsabilidad parental ante aquellos Tribunales que resulten competentes en materia de crisis matrimoniales; o, en el mismo sentido, art. 3.c o 4.c.i R. 4/2009, esta vez respecto de reclamaciones de alimentos y pensión compensatoria).
} 
residual", al considerar que,

si de los arts. 3, 4 y 5 (del R. 2201) no se deduce la competencia de ningún órgano jurisdiccional de un Estado miembro, la competencia se determinará, en cada Estado miembro, con arreglo a las leyes de dicho Estado. (Fernández y Sánchez, 2016, p. 451).

El art. 7 R. 2201, dedicado a la competencia residual, dice así al completo:

1.- Si de los artículos 3, 4 y 5 no se deduce la competencia de ningún órgano jurisdiccional de un Estado miembro, la competencia se determinará, en cada Estado miembro, con arreglo a las leyes de dicho Estado. 2.- Todo nacional de un Estado miembro que tenga su residencia habitual en el territorio de otro Estado miembro podrá, al igual que los nacionales de este último, invocar en dicho Estado las normas sobre competencia que sean aplicables en el mismo contra una parte demandada que no tenga su residencia habitual en el territorio de un Estado miembro y que no tenga la nacionalidad de un Estado miembro o, en lo que respecta al Reino Unido e Irlanda, no tenga su domicile en el territorio de uno de estos dos Estados.

El régimen autónomo español de competencia judicial internacional en la materia se halla representado por el art. 22 ter LOPJ y, especialmente, por el art. 22 quater c) LOPJ, tras reforma operada por la Ley Orgánica 7/2015, de 21 de julio, por la que se modifica la Ley Orgánica 6/1985, de 1 de julio, del Poder Judicial'10, que sustituyen a los anteriores arts. 22.2 y 22.3 LOPJ y que vienen a establecer lo siguiente: además de "cuando el demandado tenga su domicilio en España" (art. 22 ter LOPJ), los Tribunales españoles serán competentes

en materia de relaciones personales y patrimoniales entre cónyuges, nulidad matrimonial, separación y divorcio y sus modificaciones, siempre que ningún otro Tribunal extranjero tenga competencia, cuando ambos cónyuges posean residencia habitual en España al tiempo de la interposición de la demanda o cuando hayan tenido en España su última residencia habitual y uno de ellos resida allí, o cuando España sea la residencia habitual del demandado, o, en caso de demanda de mutuo acuerdo, cuando en España resida uno de los cónyuges, o cuando el demandante lleve al menos un año de residencia habitual en España desde la interposición de la demanda, o cuando el demandante sea español y tenga su residencia habitual en España al menos seis meses antes de la interposición de la demanda, así como cuando ambos cónyuges tengan nacionalidad española (art. 22 quater c LOPJ).

El régimen anterior a la reforma, por su parte, concedía competencia judicial internacional a los Tribunales españoles en

materia de relaciones personales y patrimoniales entre cónyuges, nulidad matrimonial, separación y divorcio cuando ambos cónyuges posean residencia habitual en España al tiempo de la demanda o el demandante sea español y tenga su residencia habitual en España, así como cuando ambos cónyuges tengan la nacionalidad española, cualquiera que sea su lugar de residencia, siempre que promuevan su petición de mutuo acuerdo o uno con el consentimiento del otro (art. 22.3 LOPJ anterior).

Y "con carácter general, cuando las partes se hayan sometido expresa o tácitamente a los Juzgados o Tribunales españoles, así como cuando el demandado tenga su domicilio en España" (art. 22.2 LOPJ anterior).

Expuesto lo anterior, este trabajo se va a ocupar de analizar brevemente la mayor o menor bondad de la reciente reforma de las normas domésticas españolas de competencia judicial internacional en materia de crisis matrimoniales en su comparación con la derogada, con la intención de determinar si mejora el sistema o, por contrario, no existía necesidad alguna de modificar un régimen anterior que funcionaba correctamente. Para ello, analizaremos, en primer lugar, en qué supuestos cabe la posibilidad de valorar la competencia judicial

${ }^{10}$ BOE de 22 de julio de 2015. 
internacional de los tribunales españoles en esta materia a partir de sus foros autónomos, aun cuando su vinculación al Reglamento 2201/2003 (punto I); y, en segundo término, veremos cómo se proyectan los nuevos foros de competencia en materia de crisis matrimoniales en comparación con los anteriores, a fin de determinar su mayor o menor bondad (punto II).

\section{Aplicación de los foros domésticos de competencia judicial internacional en materia de crisis matrimoniales}

\subsection{Carácter inter partes del Reglamento $2201 / 2003$}

Lavinculación de los operadoresjurídicos de los Estados miembros por las distintas normativas comunitarias no va a suponer necesariamente la inaplicación de las reglas nacionales o domésticas relativas a la materia que se trate: la supervivencia de las normas autónomas va a depender, con carácter general, de la naturaleza universal o inter partes de la normativa comunitaria vigente. En aquellos casos en los que la norma comunitaria viene revestida de carácter universal, esto es, ausente la exigencia de reciprocidad, únicamente sus reglas, y nunca las propias del derecho doméstico, resultarán aplicables al caso, lo que va a suponer que el operador jurídico va a valorar su eventual competencia judicial internacional a partir solo de las reglas del Reglamento correspondiente. Es lo que sucede, por ejemplo, con el Reglamento 4/2009 en materia de obligaciones alimenticias, cuyo ámbito de aplicación espacial es universal, al disponer que "el hecho de que el demandado tenga su residencia habitual en un Estado tercero debería dejar de ser causa de inaplicación de las reglas comunitarias de competencia, y, en adelante, debería excluirse toda remisión a las reglas de competencia del Derecho nacional" (Considerando núm. 15 R. 4/2009) ${ }^{11}$.

Por el contrario, otros instrumentos se ubican en el ámbito de los regímenes inter partes, lo que deja espacio a la aplicación del derecho autónomo respecto de aquellas situaciones consideradas como extracomunitarias de acuerdo con las reglas de cada instrumento y en contraposición a las definidas como intracomunitarias. Es lo que sucede, por ejemplo, con el Reglamento (UE) núm. 1215/2012, del Parlamento Europeo y del Consejo, de 12 de diciembre de 2012, relativo a la competencia judicial, el reconocimiento y la ejecución de resoluciones judiciales en materia civil y mercantil'2: al margen de las excepciones correspondientes, el domicilio del demandado en un Estado parte, que es el criterio empleado por el legislador comunitario como determinante de su ámbito de aplicación espacial, obliga al operador jurídico del Estado UE a valorar su competencia de acuerdo con las reglas del Reglamento 1215/2012, empleando las reglas de su derecho autónomo, en cambio, de ubicarse el domicilio del demandado en un tercer Estado (arts. 4 a 6 R. 1215). En cualquier caso, en instrumentos como este, el domicilio del demandado no opera realmente como un criterio determinante de su aplicabilidad, sino, de manera más apropiada, como un criterio de selección de normas (las propias del instrumento o aquellas de derecho autónomo) a partir de las cuales el órgano jurisdiccional de un Estado UE va a valorar su competencia: la evaluación del ámbito espacial parte de la aplicabilidad del instrumento que se trate, esto es, solo tiene sentido una vez que se ha

\footnotetext{
${ }^{11}$ Así, respecto de instrumentos como el Reglamento 4/2009 que no condicionan la aplicabilidad de sus normas a la domiciliación/ residencia habitual del demandado en un Estado UE, véase: Rodríguez (2010), especialmente par. II.1; Ancel y Muir (2010, p. 480); o Garau (2011, p. 134). También es así en sede de ley aplicable, por ejemplo, el Reglamento (CE) núm. 593/2008, del Parlamento y del Consejo, de 17 de junio de 2008, sobre la ley aplicable a las obligaciones contractuales (Roma I) (DOCE L 177, de 4 de julio de 2008), cuando su art. 2 Roma I habla de su ámbito de aplicación universal, al disponer que "la ley designada por el presente Reglamento se aplicará aunque no sea la de un Estado miembro".

12 Reglamento (UE) núm. 1215/2012, del Parlamento Europeo y del Consejo, de 12 de diciembre de 2012, relativo a la competencia judicial, el reconocimiento y la ejecución de resoluciones judiciales en materia civil y mercantil (DOCE L-351/1, de 20 de diciembre de 2012).
} 
decidido la aplicación de tal régimen, lo que sucede tras la verificación de su ámbito material y temporal ${ }^{13}$.

El Reglamento 2201/2003 regulador de la competencia judicial internacional en materia de crisis matrimoniales se encuentra dentro de este segundo grupo de normas comunitarias, lo que implica la existencia de un espacio para el juego de los foros domésticos en este ámbito. Es lo que se deduce de lo expuesto en los arts. 6 y 7 R. 2201, dedicados a la determinación del ámbito de aplicación espacial de este instrumento. El art. 6 R. 2201, relativo al "carácter exclusivo de las competencias definidas en los artículos 3, 4 y 5", establece que "un cónyuge que: ... tenga su residencia habitual en el territorio de un Estado miembro, o bien... sea nacional de un Estado miembro... sólo podrá ser requerido ante los órganos jurisdiccionales de otro Estado miembro en virtud de los artículos 3, 4 y 5", mientras que su art. 7 R. 2201, relativo, como vimos, a "la competencia residual", estima que, "si de los arts. 3, 4 y 5 (del R. 2201) no se deduce la competencia de ningún órgano jurisdiccional de un Estado miembro, la competencia se determinará, en cada Estado miembro, con arreglo a las leyes de dicho Estado".

Como veremos a continuación, no es sencilla la interpretación de los arts. 6 y 7 R. 2001, propiciada fundamentalmente por una redacción bastante confusa del precepto. De ahí que en la Propuesta de modificación del Reglamento 2201/2003 se haya modificado el tenor de estos artículos, refundiéndolos en uno solo, lo que, aunque el ámbito de aplicación espacial del Reglamento 2201/2003 se mantiene inalterado, sin duda ayuda a su comprensión. El tenor propuesto de un eventual futuro art. 6 R. 2201, dedicado asimismo a la "competencia residual", establece que:

1.- Si de los artículos 3,4 y 5 no se deduce la competencia de ninguna autoridad de un Estado miembro, la competencia se determinará, en cada Estado miembro, con arreglo a las leyes de dicho Estado miembro. 2.- El apartado 1 no se aplicará al demandado que: a) tenga su residencia habitual en el territorio de un Estado miembro, o bien b) sea nacional de un Estado miembro o, en el caso del Reino Unido y de Irlanda, tenga su domicile en el territorio de uno de estos dos Estados miembros. 3.- Todo nacional de un Estado miembro que tenga su residencia habitual en el territorio de otro Estado miembro podrá, al igual que los nacionales de dicho Estado miembro, invocar en dicho Estado las normas sobre competencia que sean aplicables en el mismo contra una parte demandada que no tenga su residencia habitual en el territorio de un Estado miembro y que no tenga la nacionalidad de un Estado miembro o, en lo que respecta al Reino Unido e Irlanda, no tenga su domicile en el territorio de uno de estos dos Estados.

1.2. Aplicabilidad de las reglas domésticas de competencia judicial internacional: la competencia subsidiaria

De acuerdo con lo expuesto en el art. 6 R. 2201, los cónyuges residentes en un Estado miembro, con independencia de su nacionalidad, o aquellos que tengan nacionalidad de un Estado miembro, con independencia de su residencia, solo pueden ser llamados ante los tribunales o autoridades de otro Estado miembro a partir de las reglas del Reglamento 2201/2003, básicamente, los foros de competencia recogidos en el art. 3 R. 2201. En consecuencia y respecto de estos casos, los órganos jurisdiccionales o autoridades de un Estado UE valorarán su competencia judicial internacional respecto de una demanda de separación judicial, divorcio o nulidad matrimonial a partir, pues y exclusivamente, de las reglas del Reglamento 2201/2003.

Piénsese, en este sentido y por ejemplo, en un matrimonio celebrado en España entre un nacional español y una nacional belga, que llevan residiendo varios años en una ciudad española y en el que, por las desavenencias surgidas, el cónyuge extranjero decide regresar a su país de origen, donde fija su nueva residencia habitual, mientras que el cónyuge español solicita disolución del vínculo ante los tribunales españoles. Tanto la nacionalidad comunitaria del cónyuge requerido, como lo sería también su residencia habitual

\footnotetext{
${ }^{13}$ Así, por ejemplo, Fernández y Sánchez (2016, p. 73), cuando entienden que "en puridad, el Reglamento (1215 o 44) se aplica espacialmente en todos los supuestos...; sin embargo, no siempre se aplican sus normas".
} 
en un Estado parte, obligan al operador jurídico español a valorar su competencia exclusivamente a partir de los arts. 3 a 5 R. 2201: en este caso, la competencia judicial internacional vendría concedida a partir de la verificación en territorio español de la última residencia habitual de los cónyuges cuando uno de ellos, el nacional español, en nuestro caso, todavía reside allí en el momento de presentación de la demanda (art. 3.1.a R. 2201). El privilegio de la nacionalidad que hace el Reglamento 2201/2003 va a suponer, en consecuencia, que un cónyuge con nacionalidad de un Estado miembro solo pueda ser requerido ante las autoridades de otro Estado miembro a partir de los arts. 3 a 5 R. 2201, aun cuando ningún otro elemento conecte a este cónyuge con la UE: sería el caso de un cónyuge chileno, casado con una nacional española, que lleva varios años viviendo en Santiago de Chile, y que, por los motivos que sean (trabajo habitualmente) se instala en un Estado europeo (Francia, por ejemplo) donde decide solicitar el divorcio de su esposa española. Del mismo modo, el privilegio de la residencia habitual que hace el Reglamento 2201/2003 va a suponer, en esta misma línea, que un cónyuge con nacionalidad de un tercer Estado y residente en la UE solo pueda ser requerido ante las autoridades de otro Estado miembro a partir de los arts. 3 a 5 R. 2201, aunque ninguno de los cónyuges tenga nacionalidad comunitaria: sería el caso de un cónyuge chileno, casado con una nacional también de este país, que llevan varios años viviendo en Madrid, y que, por los motivos que sean (trabajo habitualmente), uno de ellos se instala en Francia, por ejemplo, donde decide solicitar el divorcio de su otro cónyuge también chileno.

Fuera de estos casos del art. 6 R. 2201, dejarían de operar exclusivamente las reglas del Reglamento 2201/2003, para entrar en juego, en concurrencia, los foros de competencia judicial internacional del derecho doméstico. O, lo que es lo mismo, si los cónyuges con residencia habitual o nacionalidad de un Estado miembro solo pueden ser llamados ante los tribunales de otro
Estado miembro a partir de las reglas del Reglamento 2201/2003, el derecho doméstico va a poder operar frente a nacionales de su propio Estado o frente a quienes ni residan ni tengan la nacionalidad de un Estado miembro: en este tipo de casos, las reglas del Reglamento 2201/2003 concurren con las propias del derecho autónomo (en el caso español, con el art. 22 quater c LOPJ 2015), esto es, el Reglamento 2201/2003 resulta asimismo aplicable, si bien no con carácter exclusivo (Garcimartín, 2014, p. 158) ${ }^{14}$. Ahora bien, a la hora de decidir en esta concurrencia de las reglas del Reglamento 2201/2003 con los foros domésticos de competencia judicial internacional cuáles son los criterios finalmente aplicables por parte del operador jurídico del Estado UE ante el que se interpuso la demanda, debemos seguir lo dispuesto en la STJCE de 29 de noviembre de 2007, Sundelind v. López ${ }^{15}$, cuando entiende que la aplicación del Reglamento 2201/2003 en estos supuestos de concurrencia de regímenes va a "depende[r] ...de si un órgano jurisdiccional de un Estado miembro es competente en virtud de los artículos 3 a 5 del Reglamento 2201/2003"16. Ello significa que la aplicación del derecho autónomo solo se produciría frente a nacionales de su propio Estado o frente a quienes ni residan ni tengan la nacionalidad de un Estado miembro, y ello, siempre que ninguna regla de competencia del Reglamento 2201/2003 conceda competencia a ningún juez o autoridad comunitaria, tal como dispone el art. 7 R. 2201 relativo a las competencias residuales en combinación con la referida resolución ${ }^{17}$.

Piénsese, en este sentido, en aquel matrimonio entre dos nacionales chilenos (ecuatorianos, argentinos, uruguayos...) que llevan varios años trabajando en Europa, que fijan, meses después del enlace, su residencia habitual en Santiago de Chile para iniciar una nueva vida en su país de origen. El marido regresa posteriormente a España por motivos de trabajo, donde fija su nueva residencia, y en el que, pasados varios años y por las desavenencias surgidas por la distancia, solicita

\footnotetext{
14 También Arenas (2004, p. 167) y González (2011-2013, pp. 153-154).

${ }^{15}$ STJCE de 29 de noviembre de 2007, As. C-68/07, Sundelind v. López.

${ }^{16}$ Sobre ello, Requejo (2008).

17 Sánchez (2013, p. 38).
} 
disolución del vínculo ante los tribunales españoles. En este último caso, la nacionalidad de un tercer Estado del cónyuge requerido, así como su residencia habitual también en un tercer Estado, invitan a la valoración de la competencia de los tribunales españoles a partir de sus foros domésticos, que, sin embargo y en orden a deshacer la concurrencia con las reglas del Reglamento 2201/2003, solo operarían si ningún "órgano jurisdiccional de un Estado miembro es competente en virtud de los artículos 3 a 5 del Reglamento 2201/2003" (STJCE de 29 de noviembre de 2007, Sundelind v. López). Dado que la competencia judicial internacional vendría atribuida esta vez por el hecho de la residencia habitual del demandante chileno en España después de haber residido allí desde al menos un año antes de la presentación de la demanda (art. 3.1.a R. 2201) o, incluso, por la residencia habitual de uno de los cónyuges chilenos en España de ser un caso de demanda conjunta (art. 3.1.a R. 2201), no operarían finalmente los foros domésticos en este supuesto.

Sí lo harían, en cambio, en aquel otro supuesto de un matrimonio celebrado en Marruecos entre un nacional español y una nacional marroquí, que fijan su residencia habitual en la ciudad marroquí de Casablanca y en el que, por las desavenencias surgidas, el cónyuge español regresa a su país de origen, en el que establece su nueva residencia habitual, e inmediatamente, solicita disolución del vínculo ante los Tribunales españoles. Dado que, de presentar un divorcio contencioso y no por mutuo acuerdo, ninguna de las reglas del Reglamento 2201/2003 concede competencia a ningún juez comunitario para resolver la disolución de este matrimonio, y partiendo de que el cónyuge requerido no es nacional comunitario ni tiene residencia habitual en un Estado miembro (art. 6 R. 2201), la valoración de la competencia judicial internacional debería hacerse a partir de las normas autónomas españolas, en el caso, de la LOPJ. Operaría asimismo el derecho autónomo en el supuesto de demanda de divorcio interpuesta ante un tribunal español respecto de dos cónyuges estadounidenses que contrajeron matrimonio en los Estados Unidos, que vivieron en España y que ahora desenvuelven su vida en los Estados Unidos.

Es lo que sucede, por ejemplo, en la Sent. AP de Girona de 12 de marzo de $2013^{18}$, respecto de un divorcio entre cónyuges rusos residentes en Rusia; en el Auto AP de Madrid de 25 de enero de $2008^{19}$, en relación a un divorcio contencioso entre demandante de Ecuador residente en España y demandada residente en Ecuador; o en la Sent. AP de Asturias de 16 de julio de 200920, respecto de disolución matrimonial entre marido italiano y esposa española casados en Gibraltar.

Así pues, como estamos viendo y en la consideración de la aplicación de un instrumento comunitario como es el Reglamento 2201/2003, resulta irrelevante tanto la nacionalidad de los cónyuges perteneciente a un Estado no miembro (chilena, en nuestro ejemplo), como el hecho de que el cónyuge demandado, siendo el demandante nacional comunitario o residente en un Estado miembro, tenga su residencia habitual y/o domicilio en un Estado no miembro (Santiago de Chile, en nuestro ejemplo). Téngase en cuenta, por lo que respecta a la residencia o domicilio del cónyuge (chileno) demandado en un tercer Estado, que la STJCE de 29 de noviembre de 2007, Sundelind v. López, deja claro que la aplicación del Reglamento 2201/2003 no va a "depende[r] ...de las circunstancias del demandado, sino de si un órgano jurisdiccional de un Estado miembro es competente en virtud de los artículos 3 a 5 del Reglamento 2201/2003" (FD 25); o, lo que es lo mismo, la residencia o domicilio del cónyuge demandado en un tercer Estado no produce "una norma general por la que la determinación de la competencia de los órganos jurisdiccionales de un Estado miembro en asuntos relativos al divorcio respecto de un demandado que no tiene su residencia habitual en un Estado miembro y que no es nacional de un Estado miembro, esté regida, en todos los casos, por el Derecho nacional" (FD 24; Garcimartín, 2014, p. 158).

Asíse observa, por ejemplo, en la Sent. AP de Barcelona de 18 de diciembre de 201321, respecto de un divorcio entre cónyuges búlgaros, o en el Auto AP de Madrid de

\footnotetext{
18 JUR 2013 163496.

19 JUR 2008\98362.

20 JUR 2009\351055.

${ }^{21}$ JUR $2014 \backslash 20409$.
} 
21 de noviembre de 200822, en relación a una disolución del vínculo entre cónyuges español y argentino con domicilio y residencia habitual en Argentina, que solicitan el divorcio por mutuo acuerdo al amparo del art. 777 LEC española. Por el contrario, opera incorrectamente el tribunal español en el Auto AP de Madrid de 01 de junio de $2011^{23}$, en relación a una mujer chilena que solicitó divorcio ante los tribunales españoles al tener residencia el demandante en España desde hacía más de un año inmediatamente antes de presentar la demanda (art. 3.1.a R. 2201), al considerarse incompetentes con base, además de por la nacionalidad común de los cónyuges de un tercer Estado, en la inaplicabilidad del Reglamento al hallarse el demandado domiciliado fuera de la UE.

Del mismo modo, y así como la nacionalidad comunitaria de cualquiera de los cónyuges va a suponer que solo podrán ser requeridos ante los tribunales de otro Estado miembro a partir de las reglas del Reglamento 2201/2003, la nacionalidad de un tercer Estado del cónyuge requerido o de ambos no implica necesariamente la inaplicación del instrumento comunitario y, con ello, una eventual introducción del juego de los foros domésticos de competencia: basta con que alguna regla de competencia del Reglamento 2201/2003 conceda competencia a algún juez comunitario (arts. 6 y 7 R. $2201)^{24}$.

Mucha práctica jurisdiccional española aplica correctamente las reglas del Reglamento 2201/2003 a este tipo de supuestos, como sucede, por ejemplo, en la Sent. AP de Barcelona de 31 de enero de 201425, respecto de unos litigantes de Senegal; en la Sent. $A P$ de Guadalajara de 02 de mayo de $2013^{26}$, respecto de cónyuges ecuatorianos; o en el Auto AP de Valladolid de 10 de abril de 200727, que resuelve un divorcio entre cónyuges marroquíes. Sin embargo, no opera correctamente en otros casos, como sucede en la Sent. AP de Girona de 23 de noviembre de $2012^{28}$, respecto del divorcio entre cónyuges marroquíes; en el Auto AP de Madrid de 01 de junio de 2011'29, divorcio entre cónyuges chilenos; o el Auto AP de Bizkaia de 20 de julio de 201030, respecto de un divorcio entre cónyuges de nacionalidad peruana, en los que se ignora la aplicación del Reglamento 2201/2003 con base en el erróneo argumento de no ostentar ninguno de los cónyuges la nacionalidad de un Estado miembro.

En fin, partiendo de que los arts. 6 y 7 R. 2201 determinan en qué casos el operador jurídico de un Estado UE va a valorar su competencia exclusivamente a partir de los foros del Reglamento 2201/2003 y aquellos otros en los que cabe su valoración a partir de las reglas del derecho nacional o propio, no resulta correcta la utilización simultánea de los criterios de competencia del Reglamento 2201/2003 y del derecho doméstico como base de atribución de competencia judicial internacional a un tribunal o autoridad comunitaria en aquellos casos en los que el régimen aplicable a este aspecto solo es el instrumento comunitario ${ }^{31}$ : cuando solamente una de las normativas conforma el régimen aplicable, en este caso, el Reglamento 2201/2003, no tiene sentido emplear los foros del derecho autónomo (españoles, en nuestro caso) a modo de argumento de refuerzo de la competencia ya atribuida por el otro instrumento ${ }^{32}$.

\footnotetext{
22 JUR $2009 \backslash 73491$.

23 JUR 2011 247156. Al respecto, véase González (2012).

24 González (2011-2013, p. 143).

25 JUR $2014 \backslash 52492$.

${ }^{26}$ AC $2013 \backslash 1325$.

27 JUR 2007\262864.

28 JUR $2013 \backslash 17020$.

29 JUR $2011 \backslash 247156$.

30 JUR $2010 \backslash 409486$.

${ }^{31}$ Es lo que sucedió, por ejemplo, en el Auto AP de Barcelona de 22/10/2012 (JUR 2013\10415), en relación a un divorcio por mutuo acuerdo de un matrimonio celebrado en Brasil. No es correcto afirmar la competencia en los términos de que "tanto la LOPJ, en su art. 22, como el Reglamento 2201/2003... en su artículo $3^{\circ}$, proclaman la competencia de los Tribunales españoles para conocer de los procedimientos de nulidad matrimonial, separación y divorcio, cuando ambos cónyuges posean residencia habitual en nuestro país al tiempo de la demanda".

${ }^{32}$ Criticando esta práctica, que pone en cuestión el principio de primacía del Derecho comunitario (STJUE de 15/07/2010, As. C-256/09, Purrucker), González (2011-2013, p. 143).
} 


\section{Operatividad de los foros domésticos españoles en materia de separación judicial, divorcio y nulidad matrimonial: comparativa con el régimen anterior}

\subsection{Régimen autónomo español anterior a la reforma}

Como veíamos, vigente el Reglamento 2201/2003 (o en anterior Reglamento 1347/2000), el sistema doméstico de foros de competencia judicial internacional anterior a la reforma operada por la Ley Orgánica 7/2015, de 21 de julio, concedía competencia judicial internacional a los tribunales españoles en "materia de relaciones personales y patrimoniales entre cónyuges, nulidad matrimonial, separación y divorcio, cuando ambos cónyuges posean residencia habitual en España al tiempo de la demanda o el demandante sea español y tenga su residencia habitual en España, así como cuando ambos cónyuges tengan la nacionalidad española, cualquiera que sea su lugar de residencia, siempre que promuevan su petición de mutuo acuerdo o uno con el consentimiento del otro" (art. 22.3 LOPJ anterior), y, "con carácter general, cuando las partes se hayan sometido expresa o tácitamente a los juzgados o tribunales españoles, así como cuando el demandado tenga su domicilio en España" (art. 22.2 LOPJ anterior).

De los foros domésticos expuestos, resultaba inoperativo el foro de la residencia habitual de ambos cónyuges en España al tiempo de demanda del art. 22.3 LOPJ, al estar desactivado por el Reglamento 2201/2001, en tanto que ya recogido como uno de los criterios atributivos de competencia judicial internacional en el art. 3 R. $2201^{33}$. Igual suerte corría el criterio de la nacionalidad española común de los cónyuges, atributivo de competencia a favor de los tribunales españoles, según disponía el art. 22.3 LOPJ, cualquiera que sea su lugar de residencia y siempre que promoviesen su petición de mutuo acuerdo o uno con el consentimiento del otro, en tanto que ya recogido, al igual que antes, como uno de los criterios atributivos de competencia judicial internacional en el art. 3 R. 2201 (Calvo y Carrascosa, 2014-2015, p. 203 y Sánchez, 2013, p. 40, nota 38). Lo mismo podía decirse del criterio del domicilio del demandado en España del art. 22.2 LOPJ, ubicable genéricamente también en un art. 3 R. 2201 que emplea el foro del lugar de residencia habitual del demandado (Sánchez, 2013, p. 40, nota 38 y Cano, 2002, p. 74).

Sí resultaban operativos, por el contrario, aun cuando la vigencia del Reglamento 2201/2003 y en los casos permitidos por este instrumento, el foro de la nacionalidad española del demandante con residencia habitual en España del art. 22.3 LOPJ, así como cuando ambos cónyuges se hubiesen sometido expresa o tácitamente a los tribunales españoles del art. 22.2 LOPJ.

Respecto del primero, es cierto que el art. $3 \mathrm{R}$. 2201 recoge el foro de "la residencia habitual del demandante...que sea nacional del Estado miembro en cuestión". Sin embargo, mientras que este art. 3 R. 2201 exige que este demandante nacional del Estado miembro de interposición de la demanda "haya residido allí al menos los seis meses inmediatamente anteriores a la presentación de la demanda", el art. 22.3 LOPJ no establecía referencia temporal alguna, de manera que un tribunal español podía conocer de interponer la demanda un demandante español aun cuando llevase menos de seis meses residiendo en España (Garcimartín, 2012, p. 137 y Palao, 2014, p. 466). Otra cosa es que pudiera ser considerado este criterio de competencia como exorbitante al fundamentarse en la persona del actor y no del demandado, generando una suerte de forum actoris de difícil encaje con los principios de tutela judicial

\footnotetext{
${ }^{33}$ Así, Calvo y Carrascosa (2014-2015, p 203), Sánchez (2013, p. 40, nota 38) y Cano (2002, p. 74). En la práctica, de manera equivocada, Auto Aud. Prov. de Barcelona de 25 de enero de 2005 (JUR 2005\54635), respecto de una separación contenciosa entre cónyuges de nacionalidad argelina residentes en España, empleando el órgano jurisdiccional español el art. 22.3 LOPJ para valorar su competencia en vez del Reglamento 2201/2003.
} 
efectiva de la otra parte, así como que pudiera resultar contrario al principio de no discriminación comunitario en tanto que beneficiaba exclusivamente al demandante español (Calvo, 2014-2015, p. 203 y Garcimartín, 2014, p. 158$)^{34}$.

Por lo que respecta a la competencia de los tribunales españoles con base en la elección tácita o expresa de su jurisdicción por parte de los cónyuges ${ }^{35}$, distintos argumentos avalaban esta posibilidad.

Por un lado, nada en la LOPJ prohibía el ejercicio de la autonomía de la voluntad en este ámbito de las relaciones personales y patrimoniales entre cónyuges, nulidad matrimonial, separación y divorcio ${ }^{36}$ : la alternatividad presidía la relación entre los foros especiales de competencia del art. 22.3 LOPJ y los foros generales del art. 22.2 LOPJ, de modo que un tribunal español no competente con base en un foro especial podía basar su competencia en los foros generales, tanto por el domicilio del demandado en España como, en lo que ahora interesa, por la elección expresa o tácita de su jurisdicción. Por otro, y aun cuando la tradición de exclusión de las materias propias del derecho de familia del ejercicio de la autonomía de la voluntad, a nivel internacional la tendencia era la contraria, lo que favorecía una interpretación amplia del art. 22.3 LOPJ en lo que a este criterio se refería: sirva de muestra la posibilidad de elegir los tribunales competentes en materia de obligaciones alimenticias recogida en el art. 4 R. 4/2009, la posibilidad que ofrece el art. 5 R. 1259 estableciendo que "Ios cónyuges podrán convenir en designar la ley aplicable al divorcio y a la separación judicial", o la posibilidad de elección de foro del art. 5 R. 650 en materia de sucesiones internacionales ${ }^{37}$.

Finalmente, y en lo que a sumisión expresa se refiere, no era obstáculo a este ejercicio lo dispuesto en el art. 769.4 LEC cuando entendía (entiende) nulos "Ios acuerdos de las partes que se opongan a lo dispuesto en este artículo". Este precepto tiene como función la distribución territorial interna de la competencia entre los órganos jurisdiccionales españoles una vez atribuida la competencia judicial internacional a la jurisdicción española con base en los foros relativos a la competencia judicial internacional. O, lo que es lo mismo, este precepto solo resulta operativo tras la aplicación de las normas de competencia judicial internacional, de manera que la restricción recogida en su tenor al ejercicio de la autonomía de la voluntad solo tiene sentido a la hora de la distribución territorial interna de la competencia, no a la hora de la atribución de la competencia judicial internacional, incluso cuando esta atribución de competencia judicial internacional se realizase con base en el ejercicio de la autonomía de la voluntad. Recuérdese que, con carácter general, la atribución de la competencia judicial internacional a partir de lo dispuesto en el Reglamento 2201/2003 (o de la LOPJ) se dirige a la jurisdicción española en su conjunto, esto es, la identificación del concreto juez o tribunal español territorialmente competente no corresponde a este instrumento, sino al derecho procesal autónomo de

\footnotetext{
${ }^{34}$ En la práctica, véase Sent. AP de Valencia de 03 de julio de 2003 (JUR 2003\212530), donde conocieron los Tribunales españoles en relación a una reclamación de nulidad de un matrimonio celebrado en La Habana entre el actor de nacionalidad española y la demandada de nacionalidad cubana; o Auto AP de Sevilla de 09 de julio de 1999.

${ }^{35}$ En la práctica, por ejemplo, Sent. AP de Madrid de 04 de noviembre de 1999 (AC 1999\2347), en relación a un caso de separación matrimonial en el que la competencia del Tribunal español se fundamenta en el art. 22.2 LOPJ ya que el demandante dirige demanda ante Juzgado español y la demandada que se somete tácitamente al formular reconvención solicitando como medida cautelar la separación; también, Sent. AP de Logroño de 03 de diciembre de 1997 (REDI, 2000, p. 154); o Sent. AP de Asturias de 12 de diciembre de 1994 (AC 1994/2180). También, Sent. TSJ de Cataluña de 09 de enero de 2006 (RJ/2006/3879); o Auto AP de Madrid de 21 de febrero de 1997 (RJ/1997/234).

${ }^{36}$ Así, Calvo (2014-2015, p. 203); Cano (2002, p. 74); Palao (2014, p. 466) y Sabido (2013, p. 516).

37 Reglamento (UE) núm. 650/2012, del Parlamento Europeo y del Consejo, de 4 de julio de 2012, relativo a la competencia, la ley aplicable, el reconocimiento y la ejecución de las resoluciones, a la aceptación y la ejecución de los documentos públicos en materia de sucesiones mortis causa y a la creación de un certificado sucesorio europeo (DOUE L 201, de 27 de julio de 2012); Reglamento (UE) núm. 1259/2010, del Consejo, de 20 de diciembre de 2010, por el que se establece una cooperación reforzada en el ámbito de la ley aplicable al divorcio y a la separación judicial (DOUE L 343, de 29 de diciembre de 2010).
} 
cada Estado miembro ${ }^{38}$, en nuestro caso, al art. 769 LEC (y, complementariamente, al art. 50 LEC) (Rodríguez , 2004, pp. 263-265 y Arenas, 2004, p. 58) ${ }^{39}$.

De acuerdo con lo expuesto, esta restricción del art. 769.4 LEC no impediría a los cónyuges la elección de la jurisdicción española a la hora de resolver su crisis matrimonial. En consecuencia, la jurisdicción española en su conjunto tendría competencia judicial internacional de ser elegida por los cónyuges, tanto de resultar seleccionada esta jurisdicción española con carácter general como de elegir las partes un concreto tribunal español competente. No obstante, la autonomía de la voluntad no serviría para identificar el concreto tribunal español territorialmente competente, sino que para ello habría que acudir a los criterios objetivos territoriales recogidos en el referido art. 769 LEC, entre los que no se encuentra la autonomía de la voluntad, lo que puede suponer la competencia de un órgano jurisdiccional español distinto del elegido por los cónyuges: la elección por parte de unos cónyuges chilenos de los tribunales de Madrid, por ejemplo, para resolver su divorcio, haría competentes internacionalmente a los tribunales españoles, pero no necesariamente a los de Madrid. Únicamente de no concurrir en territorio español ninguno de los vínculos territoriales recogidos en el art. 769 LEC, sí debería seguir conociendo, a título de órgano jurisdiccional español territorialmente competente, el tribunal elegido por los cónyuges (Arenas, 2004, pp. 39 y 61-62 y Sánchez, 2013, p. 40, nota 38) ${ }^{40}$.

En fin, nada impediría tampoco la sumisión tácita a favor de los tribunales españoles en tanto que la LOPJ, al margen de los argumentos ya expuestos, no exigía en orden a su operatividad la residencia habitual de ninguno de los cónyuges en España (Garcimartín, 2014, p. 158)¹.

\subsection{Régimen autónomo español tras la reforma}

Si conforme a la LOPJ anterior seguían siendo operativos, aun cuando la vigencia del Reglamento 2201/2003 y como vimos, el foro de la nacionalidad española del demandante con residencia habitual en España del art. 22.3 LOPJ, así como el foro basado en el sometimiento de ambos cónyuges a los Tribunales españoles del art. 22.2 LOPJ, el panorama es muy distinto tras la reforma de la LOPJ.

Lo que hace esta reforma de 2015, además de mantener la competencia general de los tribunales españoles cuando "el demandado tenga su domicilio en España" (art. 22 ter LOPJ 2015), es transformar un genérico art. 22.3 LOPJ, que recoge la mayoría de los foros especiales del derecho autónomo español, en una serie de preceptos dirigidos cada uno de ellos a una materia diferente, entre los que se encuentra un art. 22 quater LOPJ 2015 dedicado "a las relaciones personales

\footnotetext{
${ }_{38}$ Por ejemplo Auto AP de Madrid de 13 de marzo de 2006 (JUR 2006\149140); más dudas, Auto AP de Madrid de 20 de enero de 2009 (JUR 2009\158145). Siendo esta la regla general, tiene sus excepciones, esto es, en ciertos casos las reglas de competencia judicial internacional juegan asimismo como criterios de distribución territorial interna de la competencia. Es lo que sucede en relación al art. 5 R. 2201, relativo a la conversión de la separación judicial en divorcio: al atribuir competencia judicial internacional para la conversión al "órgano jurisdiccional del Estado miembro que hubiere dictado una resolución sobre la separación judicial", identifica directamente al concreto órgano jurisdiccional del Estado miembro, operando como criterio de competencia judicial internacional y territorial interno; y ello, aun cuando se haya perdido el vínculo que fundamentó la competencia de los tribunales españoles y, con ello, la regla de competencia territorial española (así, Rodríguez, 2004, pp. 264-265). Y, en otras materias, por ejemplo, con el art. 8.1 Reglamento (UE) núm. 1215/2012, del Parlamento Europeo y del Consejo, de 12 de diciembre de 2012, relativo a la competencia judicial, el reconocimiento y la ejecución de resoluciones judiciales en materia civil y mercantil (DOCE L 351/1, de 20 de diciembre de 2012), relativo a las competencias derivadas en supuestos de pluralidad de demandados.

${ }^{39}$ Respecto del art. 769 LEC, véase, por ejemplo, Pérez (2000).

40 También cuando la competencia de la jurisdicción española se base en la conexión subjetiva de la nacionalidad española común de ambos cónyuges del art. 3.1.b R. 2201: si no concurren en España ninguno de los criterios territoriales del art. 769 LEC, podría atribuirse competencia territorial interna al Tribunal español del domicilio que señale el demandante, respetando así el efecto útil del Derecho comunitario y el principio de tutela judicial efectiva y siempre con el límite del abuso de derecho. Al respecto, Rodríguez (2004, p. 264); González (2001, pp. 359-361) y Arenas (2004, p. 62). Asimismo, con carácter general, Amores (1989, p. 122 y nota 25) o Virgós y Garcimartín (2007, p. 55). En la práctica, sobre estas cuestiones, véase STC 61/2000, de 13/03/2000 (BOE de 14 de abril de 2000 ) o la STJCE de 15 de mayo de 1990, As. C-365/88, Kongress Agentur Hagen GmbH v. Zeehaghe BV.

${ }^{41}$ En la práctica, véase Auto AP de Madrid de 21 de noviembre de 2008 (JUR 2009\73491), respecto de la solicitud de divorcio por mutuo acuerdo entre un cónyuge español y otro argentino, con domicilio y residencia en Argentina, a través del art. 777 LEC.
} 
y patrimoniales entre cónyuges, nulidad matrimonial, separación y divorcio y sus modificaciones": de acuerdo con su tenor, el legislador español atribuye competencia judicial internacional a los tribunales españoles, como vimos,

siempre que ningún otro tribunal extranjero tenga competencia, cuando ambos cónyuges posean residencia habitual en España al tiempo de la interposición de la demanda o cuando hayan tenido en España su última residencia habitual y uno de ellos resida allí, o cuando España sea la residencia habitual del demandado, o, en caso de demanda de mutuo acuerdo, cuando en España resida uno de los cónyuges, o cuando el demandante lleve al menos un año de residencia habitual en España desde la interposición de la demanda, o cuando el demandante sea español y tenga su residencia habitual en España al menos seis meses antes de la interposición de la demanda, así como cuando ambos cónyuges tengan nacionalidad española.

El tenor de este precepto, en combinación con lo dispuesto en el Reglamento 2201/2003, conlleva la inoperatividad práctica de este art. 22 quater c LOPJ 2015.

Primero. Porque este art. 22 quater c LOPJ, como puede verse, no es sino una copia de los foros del Reglamento 2201/2003, cuyos criterios son trasladados por el legislador español a la hora de confeccionar la regla autónoma, de manera que no solo los foros se solapan, sino que se les resta operatividad (Fernández y Sánchez, 2016, p. 451). Por un lado, con la copia se consigue seguir haciendo inaplicables los foros de derecho autónomo que ya recogía el anterior art. 22.3 LOPJ, que ahora se mantienen en el art. 22 quater c LOPJ y que ya eran idénticos a los propios del Reglamento 2201/2003, en tanto que la competencia atribuida ex Reglamento implica la imposibilidad de que un operador jurídico comunitario pueda atender a sus foros de derecho nacional para justificar su competencia a título de competencia subsidiaria ${ }^{42}$. Por otro, con la copia de los foros del Reglamento 2201/2003 también se modifican aquellos otros criterios de derecho doméstico recogidos en la versión anterior de la LOPJ que sí diferían de los ofertados por el instrumento comunitario, eliminando cualquier posibilidad de aplicar el art. 22 quater c LOPJ 2015 para hacer competentes a los tribunales españoles ex art. 7 R. 2201. Es lo que sucede, por ejemplo, al eliminar la ausencia de referencia temporal que era propia del art. 22.3 LOPJ y condicionar ahora la residencia habitual a un plazo mínimo de seis meses en España para los demandantes españoles, equiparándolo así al foro del art. 3.1.a R. 2201 y, con ello, haciendo imposible poder fundamentar la competencia en el derecho autónomo con base en un criterio antes operativo y que podía resultar útil en algunas ocasiones ${ }^{43}$. $Y$ todo ello sin entrar en los inexplicables defectos formales recogidos en un precepto copiado, como sucede en este art. 22 quater c LOPJ cuando hace referencia a "que el demandante lleve al menos un año de residencia habitual en España desde la interposición de la demanda", y no antes, lo que podría ser calificado como un lapsus calami que debe corregirse por vía interpretativa (Garcimartín, 2015, par. VII.1.).

Segundo. Porque emplear criterios de competencia semejantes en los foros domésticos generales (art. 22 bis LOPJ) y en los especiales (art. 22 quater c LOPJ) supone restar aplicación a estos últimos. Tiene poco sentido decir que el art. 22 quater c LOPJ se aplica "en defecto de los criterios anteriores", esto es, como subsidiario del foro general del domicilio (residencia habitual) del demandado en España, para más tarde establecer como criterio

\footnotetext{
${ }^{42}$ Esto no sucede con otros instrumentos comunitarios, como con el Reglamento 1215/2012. Como vimos, las reglas de Reglamento son aplicables, con carácter general, a la hora de valorar la competencia respecto de demandados domiciliados en Estados UE, mientras que las reglas de derecho autónomo operarían respecto de demandados en terceros Estados (arts. 4 a 6 R. 1215). Pensemos en un art. 22 quinquies b LOPJ cuando hace competentes a los tribunales españoles "en materia de obligaciones extracontractuales, cuando el hecho dañoso se haya producido en territorio español" (o el art. 22 quinquies a LOPJ, que hace lo propio "en materia de obligaciones contractuales, cuando la obligación objeto de la demanda se haya cumplido o deba cumplirse en España"): aunque emplean criterios semejantes a los arts. 7.2 o 7.1 R. 1215, obligaciones extracontractuales y contractuales, respectivamente, son plenamente operativos respecto de demandados domiciliados en terceros Estados.

${ }^{43}$ En este sentido, Garcimartín (2014, p. 158) o Garcimartín (2015, par. VII.1), cuando entiende la utilidad del precepto anterior al cubrir ciertos casos sociológicamente relevantes.
} 
de conexión del foro especial la residencia habitual del demandado en territorio español o la residencia habitual de ambos cónyuges en España (Garcimartín, 2015, par. VII.1.).

Tercero. Si bien puede ser legítimo copiar los criterios de competencia empleados por un instrumento comunitario, no puede olvidarse que el foro doméstico creado no es una norma multilateral, sino unilateral, de modo que tiene poco sentido proceder a una copia sin matices o sin reflexión. Es lo que sucede con la exigencia que establece el art. 22 quater c LOPJ de conceder competencia a los tribunales españoles de verificarse en España algunos de los criterios empleados en el precepto y seguidamente condicionarla al hecho de que "ningún otro tribunal extranjero tenga competencia", que puede tener sentido en el ámbito de un Reglamento 2201/2003 que apela al juego residual de los foros de competencia domésticos, pero que no lo tiene en el ámbito del derecho nacional (Fernández y Sánchez, 2016, p. 451 y Garcimartín, 2015, par. VII.1.). Los foros especiales por razón de la materia tienen su razón de ser a la hora de poder atribuir competencia a los tribunales españoles con base en vínculos de proximidad con el ordenamiento jurídico español cuando no se verifica en territorio español el criterio de competencia general, esto es, el domicilio del demandado en España: difícilmente un tribunal español podrá conocer, de condicionar su competencia al hecho de que ningún tribunal extranjero sea competente, cuando lo habitual es que los tribunales extranjeros del domicilio del demandado (que no está en España) sí lo sean. Ello implicaría, además, que un tribunal español, competente por el art. 3 R. 2201 respecto de una reclamación de separación judicial y/o divorcio, no pudiese conocer de la liquidación de su régimen económico matrimonial, cuyos criterios de competencia en el derecho doméstico español son los mismos que para las causas matrimoniales, por el hecho de que otro tribunal extranjero pudiera ser competente. Recuérdese, al respecto, que, dado que el legislador español trasladó los criterios de competencia del Reglamento 2201/2003 al derecho autónomo y que lo hizo sin modificar el título original de su foro de competencia doméstico ("relaciones personales y patrimoniales entre cónyuges"), extendió esos mismos foros a materias que quedan fuera del ámbito de aplicación del Reglamento 2201/2003, las patrimoniales, reguladas ahora por el derecho doméstico a la espera de la aplicación de los reglamentos comunitarios correspondientes ${ }^{44}$. Una condición como la referida elimina cualquier posibilidad de consideración del art. 22 quater c LOPJ, además de resultar inconsistente con los instrumentos comunitarios, lo que podría aconsejar, como mejor respuesta, su no existencia ${ }^{45}$.

Cuarto. Porque el criterio de sumisión expresa del actual art. 22 bis LOPJ, que podía tener operatividad como foro residual al hilo del art. 7 R. 2201, deja de tenerla desde el momento en que el legislador español incluyó como condición de aplicación que se trate de materias "en que una norma expresamente lo permita", lo que no sucede respecto de las crisis matrimoniales.

Piénsese que la aplicación de los diferentes reglamentos comunitarios, que incluyen la regulación de la sumisión expresa en su articulado, deja poco margen de actuación en este ámbito al derecho doméstico, más todavía cuando estos instrumentos comunitarios tienen un carácter universal $\mathrm{o}$, de no tenerlo, sí conceden excepcionalmente a algunos de sus preceptos, entre los que se encuentran habitualmente los reguladores del ejercicio de la autonomía de la voluntad, este carácter. Es lo que sucede con el art. 25 R. 1215, aplicable a las cláusulas de jurisdicción en materia civil y mercantil con independencia del domicilio de las partes (Dickinson y Lein, 2015, pp. 282-283); de los arts. 4 y 5 R. 4/2009, en

\footnotetext{
${ }^{44}$ Véanse las notas anteriores en su referencia al el Reglamento (UE) 2016/1103, del Consejo, de 24 de junio de 2016, por el que se establece una cooperación reforzada en el ámbito de la competencia, la ley aplicable, el reconocimiento y la ejecución de resoluciones en materia de regímenes económicos matrimoniales.

${ }^{45}$ Véase, sobre este punto, Garcimartín (2015, par. VII.1.), cuando estima que una lectura constitucional de la norma llevaría a una interpretatio abrogans de esa condición y tratarla como "un despiste legislativo que se debe tener por no puesto". También, Fernández y Sánchez (2016, p. 451), cuando entienden que esta mención resulta "literalmente absurda en su generalidad".
} 
sede de obligaciones alimenticias; o del art. 5 R. 650 en materia de sucesiones internacionales. El art. 22 bis LOPJ podría operar, en consecuencia, en materia de relaciones patrimoniales entre cónyuges o de establecimiento de la filiación, en tanto que no hay regulación comunitaria o, habiéndola, todavía no es aplicable, como es el caso de las relaciones patrimoniales entre cónyuges; o, en lo que ahora interesa, como foro residual en materia de crisis matrimoniales operativo ex art. 7 R. $2201^{46}$.

Pues bien, al incluir el legislador español como condición de aplicación del art. 22 bis LOPJ que se trate de materias "en que una norma expresamente lo permita", resta utilidad a este precepto al expulsarlo de los pocos márgenes libres que le quedaban por la impronta del derecho comunitario en tanto que no existe norma expresa alguna que permita el juego de la autonomía de la voluntad en esta materia (Garcimartín, 2015, par. VII.1.). Con todo, no es muy claro el art. 22 bis LOPJ a la hora de decidir en qué materias podría operar la sumisión en el derecho doméstico, esto es, en qué materias existe (o no) una norma que "expresamente lo permita", cuando solo establece que "no surtirán efectos los acuerdos que atribuyan la competencia a los tribunales españoles ni las estipulaciones similares incluidas en un contrato si son contrarios a lo establecido en los artículos 22 quáter, 22 quinquies, 22 sexies y 22 septies".

Sí operaría en el ámbito del art. 22 quinquies LOPJ, dedicado a materias de corte patrimonial. Tal es así porque el art. 22 bis.1 LOPJ dispone que "la sumisión a los tribunales españoles en las materias contempladas en las letras d) y e) del artículo 22 quinquies sólo será válida si se fundamenta en un acuerdo de sumisión posterior a que surja la controversia, o ambos contratantes tuvieran ya su domicilio o residencia habitual en España en el momento de celebración del contrato o el demandante fuera el consumidor, asegurado o tomador del seguro", con lo que viene a establecer una limitación al juego de la sumisión expresa en materias de consumo y seguros que, a sensu contrario, significa su operatividad sin límites en el resto de materias de este art. 22 quinquies LOPJ, más todavía cuando este precepto viene encabezado por la expresión "en defecto de sumisión expresa o tácita y aunque el demandado no tuviera su domicilio en España, los tribunales españoles serán competentes". No operaría la sumisión expresa del art. 22 bis LOPJ, en cambio, en las materias del art. 22 quater LOPJ, dedicado al derecho de la persona y la familia, con la excepción de la materia relativa a sucesiones, donde se admite una prorrogación de foro con restricciones, entre las que se encuentran las crisis matrimoniales del art. 22 quater c LOPJ: no solo porque este artículo viene encabezado de manera distinta que el art. 22 quinquies LOPJ, al emplear el legislador el tenor de "en defecto de los criterios anteriores, los Tribunales españoles serán competentes", también porque, frente al principio dispositivo de la materia patrimonial, el principio inquisitivo preside el derecho de familia ${ }^{47}$.

\footnotetext{
${ }^{46}$ Hasta la aplicación del Reglamento (UE) 2016/1103 del Consejo, de 24 de junio de 2016, por el que se establece una cooperación reforzada en el ámbito de la competencia, la ley aplicable, el reconocimiento y la ejecución de resoluciones en materia de regímenes económicos matrimoniales, que se producirá a partir del 29 de enero de 2019 (art. 69), deben seguir aplicándose las reglas de derecho autónomo español relativas a la competencia judicial internacional, la ley aplicable, y el reconocimiento y ejecución de resoluciones en materia de regímenes económico-matrimoniales. Por otra parte, y dado que el art. 26 R. 1215 en materia civil y mercantil no hace referencia alguna a la domiciliación de las partes en un caso de sumisión tácita, ciertos autores consideran su aplicabilidad con independencia del domicilio de cualquiera de las partes en un Estado UE (así Fernández y Sánchez, 2016, p. 89) frente a otros que entienden operativo el precepto solo respecto de demandados con domicilio en la UE (así, Garcimartín, 2014, p. 193), de modo que, en este último caso, sí podría operar el art. 22 bis LOPJ.

${ }^{47}$ Respecto de estos argumentos, véase Fernández y Sánchez (2016, p. 114), que añaden, además, la ausencia de justificación de esta limitación o ausencia del juego de la autonomía de la voluntad en materias de derecho de la persona o familia.
} 


\section{Conclusiones}

Tiene poco sentido proceder a una modificación tan importante de las reglas de competencia judicial internacional del derecho doméstico español como la operada recientemente como para elaborar, con carácter general, unas normas, muchas de ellas no solo muy defectuosas técnicamente, sino de recorrido muy corto o prácticamente nulo. No decimos que el anterior sistema de competencia doméstico perfilado básicamente en el art. 22 LOPJ no mereciese modificaciones (derogatio fori, foro de necesidad, pluralidad de demandados...), sino que las exigía de manera más puntual y menos global, en tanto que venía cubriendo las necesidades básicas que a un régimen autónomo de competencia judicial internacional se le requiere. Lo que sucede con el art. 22 quater c LOPJ en materia de crisis matrimoniales no es más un ejemplo de lo expuesto, desafortunadamente no único (competencias exclusivas, foro relativo a las obligaciones contractuales, foro de filiación...), lo que cuestiona la bondad de una reforma tanto a nivel global como puntual, más todavía cuando, a nuestro entender, no mejora necesariamente el régimen anterior de competencia judicial internacional, tampoco y en lo que ahora interesa, en sede de causas matrimoniales. No resulta extraño pensar, pues, que para este viaje tal vez no hacían falta tantas alforjas.

\section{Referencias}

Amores Conradi, M. (1989). La nueva estructura del sistema español de competencia judicial internacional en el orden civil: art. 22 LOPJ. REDI, 41, 113-156.

Ancel, B. \& Muir Watt, H. (2010). Aliments sans frontières. Le règlement CE n 4/2009 du 18 décembre 2008 relatif à la compétence, la loi applicable, la reconnaissance et l'exécution des décisions et la coopération en matière d'obligations alimentaires. Rev. cr. dr. int. pr., 3, 457-484.

Arenas García, R. (2004). Crisis matrimoniales internacionales (nulidad matrimonial, separación y divorcio en el nuevo Derecho internacional privado español): De Conflictu Legum. Santiago de Compostela: USC.

Borrás Rodríguez, A. (1998). Informe Explicativo del Convenio celebrado con arreglo al art. K.3 del Tratado de la Unión Europea, sobre la competencia, el reconocimiento y la ejecución de resoluciones judiciales en materia matrimonial. DOUE C 221/27, de 16 de julio de 1998.

Calvo Caravaca, A.L. y Carrascosa González, J. (2014-2015). Derecho internacional privado II (15ª ed.). Granada: Comares.

Cano Bazaga, E. (2002). El derecho de familia comunitario: la competencia judicial internacional de los tribunales españoles en materia de crisis matrimoniales y responsabilidad parental. Anuario de Derecho Europeo, (2), 67-89.

Dickinson, A. \& Lein, E. (Eds.). (2015). The Brussels I Regulation Recast. Oxford.

Fernández Rozas, J.C. y Sánchez Lorenzo, S. (2016). Derecho internacional privado (9ª ed.). Madrid: Civitas, Thomson Reuters.

Garau Sobrino, F. (2011). Las fuentes españolas en materia de obligaciones alimenticias. ¿Hacia un Derecho internacional privado extravagante? Cuadernos de Derecho Transnacional, 3 (2), 130-144.

Garcimartín Alférez, F.J. (2012). Derecho internacional privado. Madrid: Civitas, Thomson-Reuters.

Garcimartín Alférez, F.J. (2014). Derecho internacional privado ( $2^{a}$ ed.). Madrid: Civitas, Thomson-Reuters.

Garcimartín Alférez, F.J. (28 de septiembre de 2015). La competencia judicial internacional en la reforma de la Ley Orgánica del Poder Judicial. Diario La Ley, (8614) pp. 1-8. 


\section{Crisis matrimoniales y la reforma de las reglas domésticas españolas}

Gaudemet-Tallon, H. (2001). Le Reglement no 1347/2000 du Conseil du 29 mai 2000: «Compétence, reconnaissance et exécution des décisions en matiere matrimoniale et en matiere de responsabilité parentale des enfants communs". Journ. dr. int., 2, 381-430.

González Beilfuss, C. (2001). La adaptación de las normas de competencia territorial: arts. 50, 52 y 54 de la nueva LEC. AEDipr., 339-363.

González Beilfuss, C. (2012). Nota al AAP de Madrid (Sección 24) de 1 de junio de 2011. REDI, 208-211.

González Beilfuss, C. (2011-2013). La nulidad, separación y divorcio en el Derecho Internacional Privado español: cuestiones de competencia judicial internacional y ley aplicable. Cursos de Derecho internacional y Relaciones internacionales de Vitoria-Gazteiz 2011-2013, 135-194.

Orejudo Prieto de los Mozos, P. (2014). Diez años de aplicación e interpretación del Reglamento Bruselas II bis sobre crisis matrimoniales y responsabilidad parental (análisis de los aspectos de competencia judicial internacional). La Ley Unión Europea, 5-22.

Palao Moreno, G. (2014). Crisis matrimoniales internacionales y autonomía de la voluntad. En Cursos de Derecho internacional y Relaciones internacionales de Vitoria-Gasteiz 2013 (pp. 451-531). Cizur Menor, Navarra: Aranzadi.

Pérez Martín, A.J. (2000). Art. 769. En A.M. Lorca Navarrete (Dir.). Comentarios a la nueva Ley de Enjuiciamiento Civil (pp. 4077-4085). Valladolid: Lex Nova.

Requejo Isidro, M. (2008). Regulation (EC) 2201/03 and its personal scope: ECJ, November 29, 2007 Case C-68/07, Sundenlind López. En A. Bonomi \& P. Volken (Eds.). Yearbook of Private International Law (pp. 579-591). Sellier European Law Publishers.

Rodríguez Pineau, E. (2004). Algunas cuestiones sobre la aplicación del Reglamento CE 2201/2003 en España. AEDipr., 261-286.

Rodríguez Vázquez, M.A. (2010). La regulación del Reglamento 4/2009 en materia de obligaciones de alimentos: competencia judicial internacional, ley aplicable y reconocimiento y ejecución de sentencias. Revista electrónica de estudios internacionales (REEI), 19, 1-30.

Sabido Rodríguez, M. (2013). La nueva regulación del divorcio en la Unión Europea: Su proyección en Derecho Internacional Privado español. Revista de Derecho Comunitario Europeo, 499-534.

Sánchez Jiménez, M.A. (2013). El divorcio internacional en la Unión Europea (jurisdicción y ley aplicable). Cizur Menor, Navarra: Aranzadi Thomson Reuters.

Virgós Soriano, M. y Garcimartín Alférez, F.J. (2007). Derecho procesal civil internacional: litigación internacional (2ª ed.). Madrid: Civitas. 